\title{
Efeito do Nível de Energia Metabolizável da Dieta no Desempenho e Metabolismo Energético de Frangos de Corte ${ }^{1}$
}

\author{
Nilva Kazue Sakomura ${ }^{2}$, Flavio Alves Longo ${ }^{3}$, Carlos Bôa-Viagem Rabello ${ }^{3}$, Kleber Watanabe ${ }^{4}$, \\ Kleber Pelícia ${ }^{4}$, Ednardo Rodrigues Freitas ${ }^{3}$
}

RESUMO - Objetivou-se, nesta pesquisa, estudar o efeito dos níveis de energia metabolizável (EM) da dieta sobre o desempenho e o metabolismo energético de frangos de corte machos na fase de crescimento ( 22 a 43 dias de idade) em condições de temperatura ambiente. Foram utilizadas 288 aves distribuídas aleatoriamente por três níveis de energia da dieta $(3.050,3.200$ e $3.350 \mathrm{kcal} / \mathrm{kg})$ e três níveis de alimentação (ad libitum, 75 e 50\% do ad libitum), com quatro repetições de oito aves, para determinação das exigências de mantença e das eficiências energéticas. Foi utilizado o método do abate comparativo, sendo que 12 aves foram abatidas no início do ensaio experimental, para determinação da composição corporal inicial, e 144 aves foram usadas para determinação da energia metabolizável das dietas experimentais. Os níveis de energia influenciaram na ingestão de energia metabolizável (IEM) e, conseqüentemente, a retenção de energia na carcaça (ER) e a produção de calor (PC). As exigências de energia metabolizável de mantença (EMm) determinadas foram 131,$12 ; 140,96$ e $131,78 \mathrm{kcal} / \mathrm{kg}^{0,75} /$ dia para os níveis de energia alto, médio e baixo, respectivamente. O nível de energia mais alto (3.350 kcal $/ \mathrm{kg}$ ) na dieta dos frangos de corte proporcionou melhores resultados de desempenho, enquanto o médio (3.200 kcal $/ \mathrm{kg})$, melhor equilíbrio na eficiência de utilização de energia para deposição de proteína e gordura, conseqüentemente, melhor qualidade da carcaça, em decorrência da menor deposição de gordura.

Palavras-chave: eficiências de utilização da energia, exigência de energia para mantença, metabolismo energético, níveis de energia na dieta

\section{Effect of Dietary Metabolizable Energy on Energy Metabolism and Performance in Broiler Chickens}

\begin{abstract}
The objective of this work was to study the effect of dietary ME levels on the performance and the energy metabolism of male broilers on growing phase, from 22 to 43 days old. Two hundred and eighty-eight broilers were ramdomly assigned to three energy levels $(3,050 ; 3,200$ and 3,350 kcal $/ \mathrm{kg}$ ) and three feeding levels (ad libitum, 75\% and 50\% ad libitum), with four replicates of eight birds, to determine the energy maintenance requirements and the energy efficiency utilization. The method used was the comparative slaughter. Twelve birds were sacrificed in the beginning of trial to determine the initial body composition and 144 birds were used to determine the AMEn of diets according to ME levels and feeding levels. The dietary ME levels affected the ME intake and consequently in retained body energy (RE) and heat production (HP). The maintenance metabolizable energy requirements were: 131,141 and $132 \mathrm{kcal} / \mathrm{kg}$ of W 0.75 / day for 3,350; 3,200 and 3,050 ME/kg, respectively. The highest ME level promoted better performance of the birds, however, the medium ME level provide better values of efficiency for protein deposition and for fat deposition, consequently, lower body fat composition, showing better carcass quality.
\end{abstract}

Key Words: dietary energy levels, efficiency of energy utilization, energetic metabolism, maintenance energy requirement

\section{Introdução}

Atualmente, pesquisas nas aréas de genética, nutrição e manejo buscam minimizar as perdas provocadas pelas doenças metabólicas, em decorrência do rápido crescimento do frango, bem como diminuir os custos de produção. Assim, uma área a ser explorada é o conhecimento do crescimento e do metabolismo energético destas aves, envolvendo os fatores que os afetam, bem como o aproveitamento dos demais nutrientes da dieta, facilitando, portanto, a manipulação das rações com o objetivo de melhorar as características de carcaça, favorecendo deposição de proteína e diminuindo o acúmulo de gordura.

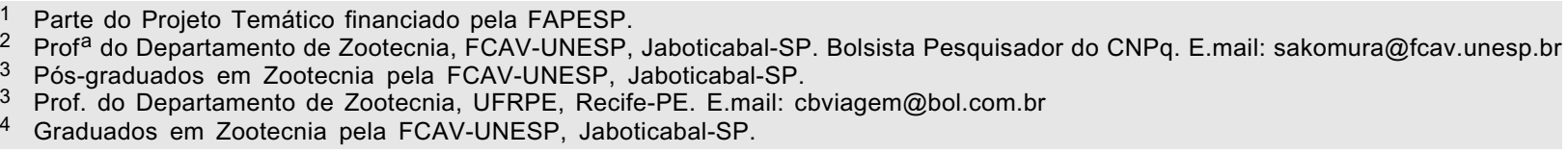


Emmans (1987) destaca a importância da determinação das exigências energéticas e das eficiências de aproveitamento da energia para frangos, principalmente quanto à eficiência em deposição de proteína e gordura, que sofrem modificações em decorrência da alimentação do próprio crescimento da ave.

Para melhor compreensão das exigências energéticas, De Groote (1974) sugere a divisão desta em gastos de energia para mantença, como processos de catabolismo e gastos de energia para produção, como processos de síntese. O catabolismo envolve gastos inevitáveis e primários, atendidos a partir da energia dos alimentos ou da oxidação de reservas corporais (trabalho de mantença, trabalho muscular e termorregulação). Além de atender às exigências para mantença, a energia ingerida também é destinada à síntese de compostos orgânicos, isto é, para o crescimento corporal, produção ou deposição de gordura. De maneira mais simples, Grimbergen (1974) divide a exigência de energia para aves em mantença e produção. A energia para mantença compreende o metabolismo basal, a produção de calor e as atividades normais, estando diretamente relacionada ao peso corporal. A energia para produção é dividida entre o crescimento e a produção de ovos.

A partir das medidas calorimétricas e dos ensaios de alimentação, determina-se o balanço energético das aves, que, de acordo com as definições de Blaxter (1989), consiste na diferença entre a energia bruta do alimento consumido e as perdas de energia pelas excretas e pela produção de calor do metabolismo, sendo definido pela equação: ER = IEM - PC, em que ER é a energia retida no corpo; IEM, a ingestão de energia metabolizável (EM), representada pela energia bruta do alimento ingerido menos a energia bruta das excretas; e PC, a produção de calor.

Considerando que parte da EM ingerida fica retida no corpo e parte é perdida como calor (incremento calórico), a proporção retida representa a eficiência de conversão da EM da dieta em energia líquida (Blaxter, 1989).

Este experimento foi conduzido com o objetivo de estudar o metabolismo energético de frangos de corte machos, por meio da determinação das exigências energéticas para manutenção e das eficiências de deposição de energia como gordura e proteína, em função de diferentes níveis de energia metabolizável na dieta.

\section{Material e Métodos}

Os experimentos foram conduzidos no Setor de Avicultura da FCAV/UNESP-Jaboticabal em condições de temperatura ambiente.

Até 21 dias de idade, todas as aves receberam uma ração atendendo às exigências nutricionais propostas no manual de criação AgRoss (1992). A partir do $22^{\circ}$ dia de idade, as dietas utilizadas foram formuladas de forma a proporcionar diferentes níveis de $\operatorname{EM}(3.050,3.200$ e $3.350 \mathrm{kcal} \mathrm{EM} / \mathrm{kg})$, mantendo a mesma relação energia:proteína e energia:aminoácidos (Tabela 1).

Foram utilizadas 444 aves - 12 aves para determinação da composição corporal aos 21 dias de idade, 288 para o ensaio de determinação das exigências e das eficiências energéticas e 144 para o ensaio de metabolismo, para determinação da energia metabolizável das dietas experimentais.

Durante todo experimento, foram registradas diariamente as temperaturas máxima e mínima, bem como a umidade relativa. Para média das máximas e mínimas, os valores de temperatura e umidade relativa foram 27,82 e $15,00^{\circ} \mathrm{C}$ e 59,25 e e $37,09 \%$, respectivamente.

$\mathrm{Na}$ determinação das exigências e das eficiências energéticas, 288 aves foram distribuídas de acordo com um delineamento inteiramente ao acaso. Os tratamentos consistiram do fornecimento de ração com três níveis de energia das rações (baixa, média e alta energia: $3.050,3.200$ e $3.350 \mathrm{kcal} / \mathrm{kg}$, respectivamente). Ao mesmo tempo, em cada um dos tratamentos estabeleceram-se grupos de aves submetidas a três níveis de alimentação (ad libitum, 75 e $50 \%$ do ad libitum). Cada parcela experimental foi constituída de quatro repetições de oito aves por tratamento. Os níveis de alimentação foram usados com o objetivo de proporcionar diferentes retenções de energia corporal, possibilitando determinar os coeficientes por meio de equações de regressão, determinando-se as exigências e eficiências de utilização da energia das diferentes dietas.

O fornecimento de ração para os grupos de aves submetidos à restrição alimentar foi realizado diariamente, em função do consumo do dia anterior do tratamento ad libitum, permitindo o controle da quantidade de alimento ingerida e da ingestão de EM.

De acordo com o procedimento de abate comparativo, foram realizados dois abates referenciais: um inicial, aos 22 dias de idade, e um final, ao término 
Tabela 1 - Composição percentual da dieta do tratamento testemunha e os níveis nutricionais utilizados nas rações Table 1 - Percentage composition of the experimental diet for the standard treatment and the nutritional levels utilized in the rations

\begin{tabular}{lccc}
\hline $\begin{array}{l}\text { Ingredientes } \\
\text { Ingredients }\end{array}$ & \multicolumn{3}{c}{$\begin{array}{c}\text { Nível de energia da ração } \\
\text { Dietary energy levels }\end{array}$} \\
\cline { 2 - 4 } & Baixa & Média & Alta \\
High
\end{tabular}

Composição calculada

Calculated composition

Energia metabolizável $(\mathrm{kcal} / \mathrm{kg})$

Metabolizable energy

Proteína bruta (Crude protein), \%

Relação EM/PB (ME:CP ratio)

Arginina (Arginine), $\%$

Lisina (Lysine), \%

Metionina (Methionine), \%

Metionina+Cistina (Methionine + cystine), \%

100,00

100,00

Treonina (Threonine), $\%$

Triptofano (Triptophan), $\%$

Gordura (Fat), \%

Cálcio (Calcium), \%

Sódio (Sodium), \%

Fósforo disponível (Available phosphorus), \%

3.050

18,10

168,51

1,18

0,99

0,51

0,71

0,68

0,21

3,71

0,91

0,19

0,40

$\begin{array}{cc}3.200 & 3.350 \\ 19,00 & 19,80 \\ 168,42 & 169,19 \\ 1,24 & 1,31 \\ 1,04 & 1,08 \\ 0,54 & 0,56 \\ 0,75 & 0,78 \\ 0,72 & 0,75 \\ 0,23 & 0,24 \\ 7,08 & 10,38 \\ 0,96 & 1,00 \\ 0,20 & 0,21 \\ 0,43 & 0,45\end{array}$

Composição analisada

Analyzed composition

Proteína bruta (Crude protein), \%

18,46

18,88

19,90

${ }^{1}$ Suplemento mineral (composição por quilograma do produto) (Mineral supplement [composition per quilogram[: $\mathrm{Fe}, 35000 \mathrm{mg} ; \mathrm{Cu}, 50000 \mathrm{mg}$; Mn, $35000 \mathrm{mg} ; \mathrm{Zn}, 30000 \mathrm{mg} ; \mathrm{I}, 600 \mathrm{mg} ; \mathrm{Se}, 90 \mathrm{mg}$.

2 Suplemento vitamínico (composição por quilograma do produto) (Vitamin supplement [composition per quilogram]: vit. A, 2300000 UI; vit. $\mathrm{D}_{3}$, 400000 Ul; vit. E, $1800 \mathrm{mg}$; vit. $K_{3}, 300$ mg; vit. $B_{1}, 150 \mathrm{mg}$; vit. $B_{2}, 1400 \mathrm{mg}$; vit. $B_{12}, 3500 \mathrm{mcg}$; ácido pantotênico (panthotenic acid), $2000 \mathrm{mg}$; ácido nicotínico (nicotinic acid), $7000 \mathrm{mg}$; piridoxina (piridoxin), $250 \mathrm{mg}$; ácido fólico (folic acid), $150 \mathrm{mg}$; biotina (biotin), $20 \mathrm{mg}$; colina (choline), $125 \mathrm{~g}$; bacitracina de zinco (Zn bacitracin), $125 \mathrm{~g} ; \mathrm{BHT}, 20 \mathrm{~g}$.

do período de coleta de dados (43 dias de idade). No abate inicial, quatro grupos de três aves foram abatidos, para determinar a composição corporal inicial, e, no abate final, foram abatidas todas as aves.

Após o abate e a depena, as aves foram congeladas e moídas integralmente para obtenção de uma amostra representativa. Posteriormente, as amostras de carcaças foram liofilizadas $\left(-30^{\circ} \mathrm{C}\right) \mathrm{e}$ encaminhadas ao laboratório juntamente com as amostras de penas, ração e excretas, para determinação dos teores de matéria seca, extrato etéreo, proteína bruta e energia bruta de acordo com a metodologia descrita por Silva (1981).

A partir dos teores médios de energia na carcaça e nas penas no início e final, foram determinados o conteúdo de energia corporal total ao início e ao final do período experimental e, por diferença, foi estimada a energia corporal retida no período.

As variáveis, ingestão de EM e energia retida, foram relacionadas segundo procedimento proposto por Farrell (1974), por intermédio de equações de regressão entre energia retida (ER) e ingestão de 
energia metabolizável (IEM), sendo estimadas as eficiências de utilização da energia da dieta para ganho de peso como sendo os coeficientes de regressão (b) da equação, IEM $=a+$ bxER.

As características de desempenho (consumos de ração, de energia e de proteína, conversão alimentar, conversão energética, conversão protéica, ganho de peso total e diário) e rendimento de carcaça e peito das aves alimentadas ad libitum foram avaliadas para os diferentes níveis de EM da dieta, no período de 22 a 43 dias de idade.

Para determinar a EMAn das dietas experimentais em cada nível de alimentação, foi conduzido o ensaio de metabolismo entre 25 e 35 dias de idade, sendo as 144 aves distribuídas inteiramente ao acaso em esquema fatorial, em função de diferentes níveis de energia $(3.050,3.200$ e $3350 \mathrm{kcal} / \mathrm{kg}$ ), sob diferentes níveis de alimentação (ad libitum, 75\% e 50\% do ad libitum), sendo quatro repetições de quatro aves por tratamento. As aves foram alojadas em gaiolas de metabolismo para quantificação da ingestão de alimento e coleta total de excretas, durante 96 horas. As análises de matéria seca, nitrogênio e energia bruta foram realizadas segundo metodologia descrita por Silva et al. (1981).

Para cada nível de energia da dieta foi analisado estatisticamente o efeito dos diferentes níveis de alimentação.

Para avaliar o fracionamento da energia retida em gordura e proteína, foram utilizados dois modelos (Boekholt et al., 1994): GP $=\mathrm{a}+\mathrm{b} \cdot \mathrm{Rp}+\mathrm{c} \cdot \mathrm{Rg}$-, para estimar as quantidades de proteína e gordura retidas no ganho de peso, e IEM $=\mathrm{EMm}+\left(1 / k_{\mathrm{p}} \mathrm{x}\right.$ ERp $)+$ $\left(1 / k_{\mathrm{g}} \times \mathrm{ERg}\right)$, para estimar o custo energético da deposição de gordura e de proteína e as eficiências de retenção. Nos modelos: GP = ganho de peso (g/dia); $\mathrm{b}=$ proporção de proteína retida no ganho de peso; $\mathrm{Rp}=$ retenção de proteína $(\mathrm{g} / \mathrm{dia}) ; \mathrm{c}=$ proporção de gordura retida no ganho de peso; $\mathrm{Rg}=$ retenção de gordura $(\mathrm{g} / \mathrm{dia}) ; \mathrm{IEM}=$ energia metabolizável ingerida $\left(\mathrm{kcal} / \mathrm{kg}^{0,75} / \mathrm{dia}\right) ; \mathrm{EMm}=$ energia metabolizável para mantença $\left(\mathrm{kcal} / \mathrm{kg}^{0}, 75 / \mathrm{dia}\right) ; \mathrm{ERp}=$ energia retida como proteína $\left(\mathrm{kcal} / \mathrm{kg}^{0,75} / \mathrm{dia}\right) ; \mathrm{ERg}=$ energia retida como gordura ( $\left.\mathrm{kcal} / \mathrm{kg}^{0,75} / \mathrm{dia}\right) ; k_{\mathrm{p}}$ e $k_{g}=$ eficiência de utilização da energia para retenção de proteína e de gordura, respectivamente.

As análises estatísticas foram processadas no PROC GLM do programa estatístico SAS Institute (1996).

\section{Resultados e Discussão}

Os valores de EM aparente das rações para aves submetidas aos diferentes tratamentos são apresentados na Tabela 2.

Para o maior $(3.350 \mathrm{kcal} / \mathrm{kg})$ e menor $(3.050 \mathrm{kcal} / \mathrm{kg})$ níveis de energia da dieta, observa-se que os diferentes níveis de ingestão de ração ( $a d$ libitum, 75 e $50 \%$ do ad libitum) afetaram significativamente os valores determinados de energia metabolizável aparente corrigida (EMAn).

Com o nível de alimentação de 75 e $50 \%$ da ingestão de ração contendo $3.350 \mathrm{kcal} / \mathrm{kg}$, os valores de EMAn aumentaram em relação ao consumo à vontade, provavelmente, em razão do maior aproveitamento da dieta.

Por outro lado, no nível mais baixo de EM (3.050 kcal $/ \mathrm{kg})$, apenas o nível de alimentação de $50 \%$ do ad libitum proporcionou valores superiores de EMAn em relação ao tratamento com $75 \%$ do ad libitum.

Estes resultados podem estar relacionados ao menor aproveitamento da dieta quando as aves ingerem quantidades crescentes de ração, evidenciando que, quanto maior o volume de ração no trato digestório, menor a sua utilização, explicado pela diminuição na eficiência de atuação das enzimas digestivas e, conseqüentemente, menor absorção de

Tabela 2 - Valores de energia metabolizável aparente corrigida $(\mathrm{kcal} / \mathrm{kg})$ das rações experimentais determinada com as aves submetidas a diferentes níveis de alimentação

Table 2 - N-corrected apparent metabolizable energy $(\mathrm{kcal} / \mathrm{kg})$ of the experimental diets, according to the different feeding levels

\begin{tabular}{lccc}
\hline $\begin{array}{l}\text { Níveis de alimentação } \\
\text { Feeding levels }\end{array}$ & \multicolumn{3}{c}{$\begin{array}{l}\text { Níveis calculados de } \\
\text { energia da dieta }\end{array}$} \\
& \multicolumn{3}{c}{ Calculated dietary energy levels } \\
\cline { 2 - 4 } & 3.350 & 3.200 & 3.050 \\
\hline Ad libitum & $3.309 \mathrm{~b}$ & 3.196 & $3.078 \mathrm{ab}$ \\
$75 \%$ & $3.326 \mathrm{a}$ & 3.191 & $3.051 \mathrm{~b}$ \\
$50 \%$ & $3.394 \mathrm{a}$ & 3.201 & $3.111 \mathrm{a}$ \\
Médias (Means) & 3.343 & 3.196 & 3.080 \\
CV $(\%)$ & 0,54 & 1,18 & 0,50 \\
F & 24,78 & 0,06 & 4,48 \\
\hline
\end{tabular}

Médias seguidas de letras diferentes na coluna diferem significativamente pelo teste Tukey $(P<0,05)$.

Means followed by different letters in the same column are different $(P<.05)$ by Tukey test. 
nutrientes. Resultados similares foram obtidos com poedeiras (Basaglia, 1999), matrizes pesadas (Silva, 1999) e frangos de corte (Longo, 2000).

As aves submetidas ao tratamento com média energia na dieta $(3.200 \mathrm{kcal} / \mathrm{kg})$ não apresentaram diferenças quanto aos valores determinados de EMAn nos diferentes níveis de alimentação, talvez porque, neste tratamento, o consumo das aves alimentadas ad libitum foi relativamente maior, resultando, conseqüentemente, em níveis de restrição menos severos, que não influenciaram os processos de metabolização da energia bruta da ração.

Os resultados de desempenho para as aves submetidas à alimentação ad libitum são apresentados na Tabela 3. O nível de energia da ração não proporcionou efeito sobre o consumo de ração, porém, o ganho de peso e a conversão alimentar foram afetados significativamente.

Por outro lado, Leeson \& Summers (1996) afirmam que os frangos de corte demonstram grande habilidade em regular o consumo, podendo ocorrer reduções na ingestão de alimento, em decorrência de aumento na densidade energética. Entretanto, Waldroup (1996) observou que o consumo de ração reduziu com o aumento da energia na dieta, de forma não-gradual.

O ganho de peso e a conversão alimentar melhoraram significativamente com o aumento da energia da dieta, obtido com a ração contendo maior nível de óleo. Aumento no ganho de peso e melhora na conversão alimentar, associados à suplementação de gordura na ração, podem ser atribuídos ao incremento da densidade calórica, ao efeito extracalórico, que consiste no aumento da disponibilidade dos nutrientes dos ingredientes da ração, e ao efeito extra metabólico da gordura, que resulta em melhoria da eficiência energética pelo incremento da energia líquida da ração.

$\mathrm{Na}$ Tabela 4, são apresentados os resultados de composição corporal e rendimento de carcaça e peito das aves submetidas à alimentação ad libitum. Observa-se que as aves que consumiram ração com média energia apresentaram significativamente $(\mathrm{P}<0,07)$ menores teores de gordura $(35,31 \%)$, quando comparadas às aves que receberam dietas de baixa energia $(39,21 \%)$, evidenciando melhor equilíbrio nutricional para a ração com níveis médios de energia $(3.200 \mathrm{kcal} / \mathrm{kg})$.

Os valores de rendimento de carcaça e peito não foram afetados significativamente pelos níveis de energia na ração. Waldroup (1996) observou maior rendimento de carcaça com o aumento do nível de energia nas rações, diminuindo a partir de $3.227 \mathrm{kcal} / \mathrm{kg}$, e o rendimento de carne de peito foi maximizado com $3.188 \mathrm{kcal} / \mathrm{kg}$ de energia na dieta. Deaton et al. (1980), utilizando dietas com conteúdo de gordura

Tabela 3 - Desempenho das aves alimentadas ad libitum com rações de diferentes níveis de energia de 22 a 43 dias de idade (período de 21 dias)

Table 3 - Performance of broilers fed ad libitum according to the different dietary energy levels from 22 to 43 days (period of 21 days)

\begin{tabular}{|c|c|c|c|c|}
\hline \multirow[t]{2}{*}{$\begin{array}{l}\text { Parâmetros } \\
\text { Parameters }\end{array}$} & \multicolumn{3}{|c|}{$\begin{array}{c}\text { Nível calculado de energia da ração }(\mathrm{kcal} / \mathrm{kg}) \\
\text { Calculated dietary energy levels }(\mathrm{kcal} / \mathrm{kg})\end{array}$} & \multirow[t]{2}{*}{$\mathrm{CV}(\%)$} \\
\hline & 3.350 & 3.200 & 3.050 & \\
\hline Consumo de ração, g (Feed intake,g) & $3.405,44$ & $3.600,06$ & $3.557,13$ & 3,51 \\
\hline Consumo de energia, $\mathrm{kcal} / \mathrm{dia}^{1}$ (Energy intake, kcal/day) & 536,60 & 547,90 & 521,37 & 3,46 \\
\hline Consumo de proteína, g/dia ${ }^{2}$ (Protein intake,g/day) & 32,27 & 32,37 & 31,27 & 3,46 \\
\hline Conversão alimentar, g:g (Feed conversion, $g: g$ ) & $1,66 \mathrm{a}$ & $1,77 \mathrm{ab}$ & $1,88 \mathrm{~b}$ & 3,73 \\
\hline Conversão energética, kcal:g (Efficiency of energy, kcal:g) & 5,48 & 5,67 & 5,79 & 3,57 \\
\hline Conversão protéica, g:g (Protein efficiency, $g: g$ ) & 0,329 & 0,335 & 0,347 & 2,33 \\
\hline Ganho de peso, g (Body weight gain,g) & $2.058 \mathrm{a}$ & $2.030 \mathrm{ab}$ & $1.893 \mathrm{~b}$ & 3,79 \\
\hline Ganho de peso diário, g (Daily body weight gain,g) & $97,99 \mathrm{a}$ & $96,66 \mathrm{ab}$ & $90,16 \mathrm{~b}$ & 3,79 \\
\hline
\end{tabular}

Médias seguidas de letras diferentes na linha diferem significativamente pelo teste Tukey $(\mathrm{P}<0,05)$.

${ }^{1}$ Valores calculados em função do consumo diário de ração (g/ave/dia) e o nível de EMAn das dietas determinados no ensaio de metabolismo (Tabela 2).

2 Valores calculados em função do consumo diário de ração (g/ave/dia) e o nível de proteína bruta das dietas analisadas em laboratório (Tabela 1).

Means followed by different letters are different $(P<.05)$ by Tukey test.

${ }^{1}$ Values calculated based on the daily feed intake (g/bird/day) and the EMAn of diets determined in the metabolism trial (Table 2).

2 Values calculated based on the daily feed intake (g/bird/day) and the crude protein analyzed in laboratory (Table 1).

R. Bras. Zootec., v.33, n.6, p.1758-1767, 2004 (Supl. 1) 
Tabela 4 - Composição corporal e rendimentos de carcaça e peito das aves alimentadas ad libitum com diferentes níveis de energia na ração

Table 4 - Body composition and carcass and breast yield of broilers fed ad libitum, according to dietary energy levels

\begin{tabular}{|c|c|c|c|c|}
\hline \multirow[t]{2}{*}{$\begin{array}{l}\text { Parâmetros } \\
\text { Parameters }\end{array}$} & \multicolumn{3}{|c|}{$\begin{array}{l}\text { Nível calculado de energia da dieta }(\mathrm{kcal} / \mathrm{kg}) \\
\text { Calculated dietary energy levels } \mathrm{kcal} / \mathrm{kg}\end{array}$} & \multirow[t]{2}{*}{$\mathrm{CV}(\%)$} \\
\hline & 3.350 & 3.200 & 3.050 & \\
\hline \multicolumn{5}{|c|}{ Composição corporal (\%) } \\
\hline & \multicolumn{3}{|c|}{ Bodycomposition } & \\
\hline Matéria seca (Dry matter) & 33,94 & 35,42 & 35,44 & 2,78 \\
\hline Proteína bruta ${ }^{1}$ (Crude protein) & 48,14 & 47,86 & 48,76 & 3,22 \\
\hline Cinzas $^{1}$ (Ash) & 8,40 & 7,91 & 8,48 & 5,48 \\
\hline \multirow[t]{3}{*}{ Gordura $^{1}$ (Fat) } & $38,92 \mathrm{ab}$ & $35,31 \mathrm{~b}$ & $39,21 \mathrm{a}$ & 2,59 \\
\hline & \multicolumn{3}{|c|}{ Rendimento (\%) } & \\
\hline & & Yield & & \\
\hline Carcaça (Carcass) & 75,10 & 75,00 & 75,00 & 0,80 \\
\hline Peito (Breast) & 33,70 & 35,00 & 34,20 & 2,66 \\
\hline
\end{tabular}

${ }^{1}$ Valores expressos na matéria seca (Values in dry matter basis).

Médias seguidas de letras diferentes na linha diferem $(P<0,07)$ significativamente pelo teste de Tukey.

Means followed by different letters are different $(P<.07)$ by Tukey test.

Tabela 5 - Médias de ingestão de energia metabolizável (IEM), energia retida (ER) e produção de calor (PC) das aves submetidas a diferentes níveis de energia e alimentação

Table 5 - Metabolizable energy intake (MEI), retained energy $(E R)$ and heat production $(P C)$ of birds according to the different energy and feeding levels

\begin{tabular}{|c|c|c|c|c|}
\hline Níveis de energia da dieta & Níveis de alimentação & IEM & ER & $\mathrm{PC}$ \\
\hline Dietary energy levels & Feeding levels & \multicolumn{3}{|c|}{$\begin{array}{c}\left(\mathrm{kcal} / \mathrm{kg}^{0,75} / \mathrm{dia}\right) \\
\left(\mathrm{kcal} / \mathrm{kg}^{0.75} / \text { day }\right)\end{array}$} \\
\hline \multirow[t]{3}{*}{3.350} & Ad libitum & 368,61 & 160,58 & 208,03 \\
\hline & $75 \%$ & 307,31 & 111,81 & 195,49 \\
\hline & $50 \%$ & 240,67 & 74,99 & 165,67 \\
\hline \multirow[t]{3}{*}{3.200} & Ad libitum & 379,67 & 156,58 & 223,10 \\
\hline & $75 \%$ & 315,13 & 119,93 & 195,19 \\
\hline & $50 \%$ & 239,30 & 63,45 & 175,85 \\
\hline \multirow[t]{3}{*}{3.050} & Ad libitum & 371,21 & 162,11 & 209,10 \\
\hline & $75 \%$ & 304,14 & 115,82 & 188,32 \\
\hline & $50 \%$ & 237,10 & 70,03 & 167,07 \\
\hline
\end{tabular}

animal de 4, 7 e 10\%, observaram aumento linear no conteúdo de gordura na carcaça. Latour et al. (1994) afirmam que o efeito da suplementação de lipídeos na dieta de aves depende do conteúdo de proteína e que dietas com adição de gorduras são bem aproveitadas quando os níveis de proteína são elevados.

Na Tabela 5, são apresentados os dados médios de ingestão de energia metabolizável (IEM), energia retida (ER) e produção de calor (PC), em kcal/ $\mathrm{kg} 0,75 /$ dia, conforme os diferentes tratamentos. Verifica-se certa relação entre os níveis de energia da dieta e os valores de IEM e, conseqüentemente, entre a ER na carcaça e na PC. Segundo Blaxter
(1989), diferenças nas ingestões de alimento provocam reflexos na produção de calor pelo animal, sendo que o aumento no consumo de alimento acarreta incremento na produção de calor pela maior combustão da dieta.

A partir dos dados da Tabela 5, foram elaboradas equações de regressão da ER e PC, em função da IEM, com a finalidade de determinar as EMm e Elm, apresentadas na Tabela 6, na qual podem ser observados valores diferentes da exigência de EM para mantença (EMm), 131,12; 140,96 e 131,78, quando as aves foram alimentadas com os níveis de energia alto, médio e baixo, respectivamente. 
Nieto et al. (1995) apresentam, em uma revisão, valores de EMm para frangos de corte entre $73 \mathrm{e}$ $163 \mathrm{kal} / \mathrm{kg}^{0,75} / \mathrm{dia}$. Os mesmos autores, trabalhando com dieta controle, dieta com suplementação extra de lisina e dieta com suplementação de metionina para frangos de corte em crescimento, encontraram valores de EMm de 143, 126 e $111 \mathrm{kcal} / \mathrm{kg}^{0,75} / \mathrm{dia}$, respectivamente. Segundo os autores, estas diferenças estão relacionadas à composição da dieta. Por outro lado, Longo (2000), trabalhando com frangos de corte em temperaturas de 13,23 e $32^{\circ} \mathrm{C}$, determinou respectivas exigências de EMm de 157,$83 ; 112,09$ e $127,16 \mathrm{kcal} / \mathrm{kg}^{0,75} / \mathrm{dia}$.

No presente trabalho, não foram encontradas diferenças nos valores de eficiências para ganho $(\mathrm{kg})$ para os diferentes tratamentos (66, 67 e 67\%) para os níveis de alta, média e baixa energia na dieta, respectivamente. Os valores determinados são semelhantes aos obtidos por Nieto et al. (1995), que variaram de 57,2 a $66 \%$. Contudo, Boekholt et al. (1994) encontraram valores superiores (71 e 74\%), enquanto Longo (2000), resultados semelhantes (63, 59 e $66 \%$, trabalhando com frangos de corte em temperaturas de 13,23 e $32^{\circ} \mathrm{C}$, respectivamente).

Na Tabela 7, são relacionadas as médias de ganho de peso diário (GP) e de ganho diário, em gordura (GPg) e proteína (GPp), para os diferentes tratamentos. A partir destes resultados, elaboraram-se as equações de regressão múltipla do GP, em função do GPg e GPp (Tabela 8).
A variação nos coeficientes de retenção de gordura e de proteína encontrados nas diferentes equações demonstram a importância da disponibilidade de nutrientes sobre o fracionamento desse ganho. Kessler et al. (2000) comentam que a maior ou menor disponibilidade de nutrientes para as aves proporcionava diferenças nas taxas de lipogênese, resultando em mudança na composição de ganho em gordura e em proteína.

Utilizando o mesmo método de regressão dos valores do ganho de peso (GP), em função do ganho de peso em gordura (GPg) e proteína (GPp), Boekholt et al (1994) obtiveram resultados de 3,8 g de GPp e 1,1 g de GPg por grama de GP, que diferem dos resultados obtidos nessa pesquisa, provavelmente em razão das diferenças na composição da dietas, sendo o principal fator que afeta a composição do ganho de peso.

Equações de regressão múltipla relacionando a IEM em função da energia retida como gordura (ERg) e energia retida como proteína (ERp), em $\mathrm{kcal} / \mathrm{kgP}^{0,75} / \mathrm{dia}$, foram elaboradas para determinar os valores de EMm e as eficiências de utilização da energia metabolizável para retenção de gordura $\left(k_{g}\right)$ e de proteína $\left(k_{p}\right)$ (Tabela 9).

Os valores de EMm determinados por este método demonstraram novamente a maior exigência para mantença para as aves submetidas ao tratamento com média energia na dieta, que foi próxima ao valor encontrado na Tabela 6. Vale salientar que a exigência de mantença determinada por esta equação de

Tabela 6 - Equações de regressão da ER e da PC, em função da IEM e os valores de EMm e de ELm e eficiências de utilização da energia para ganho $(K g)$ e para mantença $(K m)$ das aves submetidas à ração com diferentes níveis de energia

Table 6 - Regression equations of ER and PC in function of MEI, and values of EMm and ELm and efficiencies of energy utilization for gain $(\mathrm{kg})$ and for maintenance $(\mathrm{km})$ according to the different dietary energy levels

\begin{tabular}{lccc}
\hline $\begin{array}{l}\text { Equações } \\
\text { Equations }\end{array}$ & $\mathrm{R}^{2}$ & $\begin{array}{c}\text { Exigências de mantença }\left(\mathrm{kcal} / \mathrm{kg}^{0,75} / \mathrm{dia}\right) \\
\text { Maintenance requirement }\end{array}$ & $\begin{array}{c}\text { Eficiências } \\
\text { Efficiencies }\end{array}$ \\
\hline ER $=-87,05+0,66$.IEM & 0,97 & $3.350 \mathrm{kcal} / \mathrm{kg}$ & $\mathrm{Kg}=0,66$ \\
$\mathrm{PC}=4,68+0,0018 . \mathrm{IEM}$ & 0,84 & $\mathrm{EMm}(\mathrm{MEm})=131,12$ & $\mathrm{Km}=0,82$ \\
& & $\mathrm{ELm}(\mathrm{NEm})=107,77$ & $\mathrm{Kg}=0,67$ \\
$\mathrm{ER}=-93,74+0,67 . \mathrm{IEM}$ & 0,97 & $3.200 \mathrm{kcal} / \mathrm{kg}$ & $\mathrm{Km}=0,82$ \\
$\mathrm{PC}=4,76+0,0017 . \mathrm{IEM}$ & 0,89 & $\mathrm{EMm}(\mathrm{MEm})=140,96$ & $\mathrm{Kg}=0,67$ \\
& & $3.050 \mathrm{kcal} / \mathrm{kg}$ & $\mathrm{Km}=0,84$ \\
$\mathrm{ER}=-88,65+0,67 . \mathrm{IEM}$ & 0,96 & $\mathrm{EMm}(\mathrm{MEm})=131,78$ &
\end{tabular}

$\mathrm{K}_{\mathrm{g}}$ (eficiência de ganho) $=$ coeficiente de regressão da equação $\mathrm{ER}=\mathrm{a}+\mathrm{bxIEM}$ (efficiency of gain = regression coefficient of equation $K_{\mathrm{g}}$ (eficiência de
$E R+b$. IEM).

$\mathrm{K}_{\mathrm{m}}$ (eficiência de mantença) (maintenance efficiency) $=\mathrm{ELm} / \mathrm{EMm}$.

R. Bras. Zootec., v.33, n.6, p.1758-1767, 2004 (Supl. 1) 
Tabela 7 - Médias de ganho de peso (GP), ganho em gordura (GPg) e em proteína (GPp) das aves submetidas aos diferentes níveis de alimentação e energia da ração

Table 7 - Means of body weight gain (GP), fat weight gain (GPg) and protein weight gain (GPp) of birds, according to the different dietary energy and feeding levels

\begin{tabular}{lccc}
\hline $\begin{array}{l}\text { Níveis de alimentação } \\
\text { Feeding levels }\end{array}$ & $\begin{array}{c}\text { GP(g/ave/dia) } \\
\text { (g/birds/day) }\end{array}$ & $\begin{array}{c}\text { GPg(g/ave/dia) } \\
\text { (g/birds/day) }\end{array}$ & $\begin{array}{c}\text { GPp(g/ave/dia) } \\
\text { (g/birds/day) }\end{array}$ \\
\hline & & $3.350 \mathrm{kcal} / \mathrm{kg}$ & \\
Ad libitum & $91,34 \pm 3,15$ & $12,94 \pm 0,46$ & $19,41 \pm 0,99$ \\
$75 \%$ & $63,67 \pm 1,00$ & $6,35 \pm 1,12$ & $14,33 \pm 0,68$ \\
$50 \%$ & $38,92 \pm 2,14$ & $2,90 \pm 0,86$ & $9,61 \pm 0,50$ \\
& & $3.200 \mathrm{kcal} / \mathrm{kg}$ & $20,04 \pm 0,93$ \\
Ad libitum & $88,90 \pm 3,10$ & $11,81 \pm 1,49$ & $13,70 \pm 0,24$ \\
$75 \%$ & $60,66 \pm 1,62$ & $7,73 \pm 0,91$ & $8,42 \pm 1,83$ \\
$50 \%$ & $38,52 \pm 1,35$ & $2,28 \pm 0,68$ & $19,24 \pm 0,95$ \\
& & $3.050 \mathrm{kcal} / \mathrm{kg}$ & $12,78 \pm 0,72$ \\
Ad libitum & & $12,55 \pm 0,86$ & $8,71 \pm 0,31$ \\
$50 \%$ & $82,48 \pm 3,61$ & $7,37 \pm 0,53$ & $2,64 \pm 0,75$ \\
\hline
\end{tabular}

Tabela 8 - Equações de regressão múltipla do ganho de peso (GP), em função do ganho em gordura (GPg) e em proteína (GPp)

Table 8 - Multiple linear equations of body weight gain (g), in function of fat and protein retention

\begin{tabular}{lllll}
\hline $\begin{array}{l}\text { Níveis de energia } \\
\text { Energy levels }\end{array}$ & $\begin{array}{l}\text { Equações } \\
\text { Equations }\end{array}$ & $\mathrm{R}^{2}$ & $\mathrm{GPg}$ & $\mathrm{GPp}$ \\
\hline 3.350 & $\mathrm{GP}=-4,916+0,939 \mathrm{GPg}+4,333 \mathrm{GPp}$ & 0,99 & 0,939 & 4,333 \\
3.200 & $\mathrm{GP}=12,906+2,487 \mathrm{GPg}+2,255 \mathrm{GPp}$ & 0,98 & 2,487 & 2,255 \\
3.050 & $\mathrm{GP}=10,703+3,007 \mathrm{GPg}+1,782 \mathrm{GPp}$ & 0,99 & 3,007 & 1,782 \\
\hline
\end{tabular}

Tabela 9 - Equações de regressão múltipla da EMI em função da energia retida como gordura (ERg) e proteína (ERp) e eficiências de utilização da energia para retenção de gordura $\left(k_{g}\right)$ e de proteína $\left(k_{p}\right)$ em frangos alimentados com diferentes níveis de energia na dieta

Table 9 - Multiple linear regression equations of metabolizable energy intake, in function of energy retention as fat (ERg) and protein (ERp), and efficiencies of energy retention as fat $\left(k_{g f}\right)$ and protein $\left(k_{p}\right)$ in broilers fed different energy levels

\begin{tabular}{|c|c|c|c|c|c|}
\hline $\begin{array}{l}\text { Níveis de EM } \\
\text { Energy levels }\end{array}$ & $\begin{array}{l}\text { Equações } \\
\text { Equations }\end{array}$ & $\mathrm{R}^{2}$ & $\operatorname{EMm}\left(\mathrm{kcal} / \mathrm{kg}^{0,75} / \mathrm{dia}\right)$ & $k_{g}$ & $k_{p}$ \\
\hline 3.350 & $\mathrm{IEM}=81,342+0,816 \mathrm{ERg}+2,909 \mathrm{ERp}$ & 0,97 & 81,34 & 1,23 & 0,34 \\
\hline 3.200 & $\mathrm{IEM}=147,150+1,443 \mathrm{ERg}+1,485 \mathrm{ERp}$ & 0,97 & 147,15 & 0,69 & 0,67 \\
\hline 3.050 & $\mathrm{IEM}=128,167+1,233 \mathrm{ERg}+1,799 \mathrm{ERp}$ & 0,96 & 128,17 & 0,81 & 0,56 \\
\hline
\end{tabular}


regressão considera a ingestão de energia em função da ERg e da ERp na carcaça, não sendo recomendada por Nieto et al. (1995).

$\mathrm{O}$ fato de as dietas terem sido formuladas com diferentes níveis de gordura e proporções gordura:carboidrato acarretou diferenças numéricas nos valores encontrados de eficiência de deposição de energia como gordura e proteína, entre os tratamentos (Tabela 9).

A dieta formulada com médio nível de energia proporcionou melhor equilíbrio para deposição de energia como proteína e gordura, menor eficiência numérica para deposição de gordura $(0,69)$ em relação aos outros tratamentos $(1,23$ e 0,81 para tratamentos com alta e baixa energia da dieta, respectivamente) e melhor eficiência para deposição de energia como proteína $(0,67)$.

No tratamento em que as aves foram submetidas a alto nível de energia nas dietas, conseqüência de maior nível de óleo, a eficiência para deposição de energia como proteína foi menor $(0,34)$ em relação aos demais tratamentos, porém promoveu maior eficiência de utilização de energia na deposição de gordura $(1,23)$

Boekholt et al. (1994) determinou valores de eficiência de retenção de energia como proteína e gordura de 0,66 e 0,86 , respectivamente. Por sua vez, Nieto et al. (1995), trabalhando com dietas diferentes, encontraram variação mais ampla na eficiência de utilização da energia como gordura $(0,65$ a 1,27$)$ e como proteína $(0,41$ a 0,58$)$.

Considerando a eficiência de retenção de energia como gordura e proteína e o valor calórico de gordura $(9,37 \mathrm{kcal} / \mathrm{g})$ e de proteína $(5,66 \mathrm{kcal} / \mathrm{g})$, foram estimadas as exigências de energia metabolizável para deposição de um grama de gordura $(7,65 ; 13,52$ e $11,55 \mathrm{kcal} / \mathrm{g}$ para alta, média e baixa energia da dieta, respectivamente) e um grama de proteína $(16,47$; 8,40 e $10,07 \mathrm{kcal} / \mathrm{g}$ para alta, média e baixa energia da dieta, respectivamente). Estas diferenças evidenciam que a composição da dieta, bem como a ingestão de nutrientes, influi na retenção de energia como proteína e gordura.

Longo (2000) observou valores de 10,21 a $16,96 \mathrm{kcal} / \mathrm{g}$ de gordura depositada e de 9,74 a $15,85 \mathrm{kcal} / \mathrm{g}$ de proteína depositada. Boekholt et al. (1994) relataram valores de 10,90 e $8,57 \mathrm{kcal} / \mathrm{g}$ de EM por grama de gordura e proteína depositada em frangos de corte, respectivamente.

\section{Conclusões}

Os diferentes níveis de energia das dietas, promovidos pela adição de óleo, afetaram as eficiências de utilização da energia para mantença e para deposição de proteína e de gordura corporal. O nível mais alto de energia $(3.350 \mathrm{kcal} / \mathrm{kg})$ na dieta dos frangos de corte proporcionou melhores resultados de desempenho, enquanto o nível médio de energia $(3.200 \mathrm{kcal} / \mathrm{kg})$, melhor equilíbrio na eficiência de utilização de energia para deposição de proteína e de gordura, conseqüentemente, melhor qualidade da carcaça, em decorrência da menor deposição de gordura.

\section{Literatura Citada}

AGROSS, s.d. Manual de manejo de frango de corte. Rio Claro: Agroceres Ross, 1992. 152p.

BASAGLIA, R. Equações de predição das exigências de energia e proteína para poedeiras leves. Jaboticabal: Universidade Estadual Paulista, 1999. 158 p. Tese (Doutorado em Zootecnia) - Universidade Estadual Paulista, 1999.

BLAXTER, K. Energy metabolism in animals and man. Cambrigde, 1989. 336p.

BOEKHOLT, H.A.; Van Der GRINTEN, P.H.; SCHREUS, V.V.A.M. et al. Effect of dietary energy restriction on retention of protein, fat and energy in broiler chickens. British Poultry Science, v.35, p.603-614, 1994.

DEATON, J.W.; McNAUGHTON, J.L.; REECE, F.N. et al. Abdominal fat of broilers as influenced by dietary level of animal fat. Poultry Science, v.60, p.1250-1253, 1980.

DE GROOTE, G. Utilization of metabolizable energy. In: MORRIS, T.R.; FREEMAN, B.M. (Eds.) Energy requeriments of poultry. Edinburgh: British Poultry Science, 1974. p.113-33.

EMMANS, G.C. Growth, body composition and feed intake. World's Poultry Science Journal, v.43, p.208-227, 1987.

FARRELL, D.J. General principles and assumptions of calorimetry. In: MORRIS, T.R.; FREEMAN, B.M. (Eds.), Energy requeriments of poultry. Edinburgh: British Poultry Science, 1974. p.1-23.

GRIMBERGEN, A.H.M. Energy expenditure under productive conditions. In: MORRIS, T.R.; FREEMAN, B.M. (Eds.), Energy requeriments of poultry. Edinburgh: British Poultry Science, 1974. p.61-71.

KESSLER, A.M.; SNIZEK Jr., P.N.; BRUGALLI, I. Manipulação da quantidade de gordura na carcaça de frangos. In: CONFERÊNCIA APINCO DE CIÊNCIA E TECNOLOGIA AVÍCOLAS, 2000, Campinas. Anais... Campinas: FACTA, 2000. p.107-133.

LATOUR, M.A.; PEEBLES, E.D.; BOYLE, C.R. et al. The effects of dietary on growth performance, carcass composition, and feed efficiency in the broiler chick. Poultry Science, v.73, p.1362-1369, 1994.

LEESON, S.; SUMMERS, J.D. Commercial poultry nutrition. 1.ed. Guelph: University Mooks, 1996. 350p.

LONGO, F.A. Estudo do metabolismo energético e do crescimento em frangos de corte. Jaboticabal: Universidade do 
Estado de São Paulo, 2000. 76p. Dissertação (Mestrado em Zootecnia) - Universidade do Estado de São Paulo, 2000.

NIETO, R.; PRIETO, C.; FERNANDEZ-FIGARES, I. et al. Effect of dietary protein quality on energy metabolism in growing chickens. British Journal Nutrition, v.74, p.163-172, 1995.

STATISTICAL ANALYSES SYSTEM - SAS. Guide: statistics Version 6, 12.ed. Cary: 1996.

SILVA, D.J. Análises de alimentos: métodos químicos e biológicos. Viçosa, MG: Universidade Federal de Viçosa, 1981. 166p.

SILVA, R. Equações de predição das exigências de energia e proteína para matrizes pesadas na fase de crescimento. Jaboticabal: Universidade do Estado de São Paulo, 1999. 130p. Tese (Doutorado em Zootecnia) - Universidade do Estado de São Paulo, 1999.
WALDROUP, P.W. Nutrient requirement of broilers. In: SIMPÓSIO INTERNACIONAL SOBRE EXIGÊNCIAS NUTRICIONAIS DE AVES E SUÍNOS, 1996, Viçosa, MG. Anais... Viçosa, MG: Universidade Federal de Viçosa, 1996. p.55.
Recebido em: 03/04/03

Aceito em: 30/03/04 